Intersectionality as Critical Social Theory 
This page intentionally left blank 


\section{Intersectionality as Critical Social Theory}

\section{PATRICIA HILL COLLINS}




\section{(C) 2019 DUKE UNIVERSITY PRESS}

\section{All rights reserved}

Printed in the United States of America on acid-free

\section{paper $\infty$}

Designed by Matthew Tauch

Typeset in Minion Pro and Helvetica Neue Lt Std

by Westchester Publishing Services

Library of Congress Cataloging-in-Publication Data

Names: Hill Collins, Patricia, author.

Title: Intersectionality as critical social theory / Patricia Hill Collins.

Description: Durham : Duke University Press, 2019. | Includes

bibliographical references and index.

Identifiers: LCCN 2018061091 (print) | LCCN 2019005395 (ebook)

ISBN 9781478007098 (ebook)

ISBN 9781478005421 (hardcover : alk. paper)

ISBN 9781478006466 (pbk. : alk. paper)

Subjects: LCSH: Intersectionality (Sociology) | Critical theory. | Social change. |

Social justice.

Classification: LCC HM488.5 (ebook) | LCC HM488.5 .H56 2019 (print) | DDC 303.4-dc23

LC record available at https://lccn.loc.gov/2018061091 
This book is dedicated to the memory of my parents, Eunice Randolph Hill and Albert Hill 
This page intentionally left blank 